\title{
Caterina Albert i Paradís (Víctor Català) i Rafael Marquina: autoria, traducció i interlocució literàries ${ }^{1}$
}

\section{Caterina Albert i Paradís (Víctor Català) i Rafael Marquina: Authorship, Translation and Literary Interlocution}

\author{
Dolors Madrenas Tinoco \\ Col-legi Dominiques de l'Ensenyament (Barcelona) \\ dolorsmadrenas@gmail.com \\ JOAN M. RIBERA LLOPIS \\ Universidad Complutense de Madrid \\ jumriber@filol.ucm.es
}

Recibido: mayo de 2019. Aceptado: junio de 2019

Resum: Ordenació de les traduccions al castellà de la narrativa breu de Víctor Català degudes a Rafael Marquina. L'epistolari entre ambdós permet aproparse a criteris de l'autora i a solucions del traductor a propòsit dels relats elegits. Així mateix, facilita atendre al corresponent intercanvi amb altres interlocutors de l'escriptora i contrastar els respectius punts de vista sobre el procés de la traducció, tant com la valoració que a la fi pogué merèixer la versió castellana publicada.

Paraules clau: Relacions literàries catalano-castellanes. Víctor Català i Rafael Marquina. Traducció i informació epistolar.

Abstract: Arrangement of the translations into Spanish of Víctor Català's short narrative due to Rafael Marquina. The correspondence between both allows approaching the author's criteria and the translator's solutions around the chosen stories. Likewise, it allows us to attend to the corresponding exchange with other interlocutors of the writer and to contrast the respective

\footnotetext{
1 Versió revisada i ampliada de la comunicació presentada al XVIIIè Col·loqui Internacional de Llengua i Literatura Catalanes (AILLC - Universitatea din București, entre els dies 2 i 6 de juliol de l'any 2018).
} 
points of view on the translation process as well as the valuation that the published Spanish version could deserve.

Key words: Catalan-Castilian literary relations. Víctor Català and Rafael Marquina. Translation and epistolary information.

\section{I.- TRADUCCIONS I TRADUCTORS ENTRE DOS SEGLES}

Del darrer terç del vuit-cents als primers trenta anys de la centúria següent, à l'àmbit peninsular, ibèric o hispà $i$ en la cronologia d'un cicle històric que contempla una versàtil successió de corrents literaris en bona mesura fonamentats ideològicament $\mathrm{i}$ estètica sobre la corresponent proposta anterior, una potencial xarxa interliterària semblava deixar enrere la diglòssia lingüística i cultural prèvia, al mateix temps que feia impensable l'abisme obert des de l'any trenta-nou entre les tradicions de la llar comuna. Força lligada a les relacions personals que fomentaven la coneixença mútua -arrelada sobre la base del diàleg iberista, a favor del qual les publicacions periòdiques havien anat esbrossant culturalment les opinions més agrestes-, la traducció s'alçà com l'element potser més sòlid per abastar una creixent normalitat que sistematitzés intercanvi i coneixement entre les diverses veus veïnes. De manera majoritària passant pel castellà i encara que no manquin les connexions binàries per via directa entre les altres llengües literàries peninsulars, la traducció objectivà difusament la proposta de l'altra literatura. Aquest seria el seu objecte literari que restava dipositat a les mans del receptor, a la vegada que, a posteriori, ens nodriria històrico-literàriament del pas llavors aconseguit.

En aquest espectre, la corresponent baula catalano-castellana que s'animarà $\mathrm{amb}$ el protagonisme extra-català concedit a Jacint Verdaguer a partir de la traducció de Melcior de Palau (1842-1910) de L'Atlàntida l'any 1878 i que anirà arrossegant cronologia endavant noms com els de Narcís Oller i Àngel Guimerà amb els seus representatius textos, no s'aturaria amb el modernista $f i$ de segle, amb Santiago Rusiñol com a figura senyera i més traduïda (Ribera Llopis 2007: 166-169). Es aquesta una coordenada històrica en la qual es troben l'esmentat impuls iberista amb l'atenció $i$ el respecte literàriament castellà cap l'embranzida cultural catalana. Coordenada que podem tornar a situar en el curs de l'interès de les lletres castellanes pel nostre patrimoni (Bacardi 2010), així com es pot justificar en la convergència finisecular de fonaments i criteris entre els representants d'una transversal vida cultural en una compartida comunitat interliterària (Ribera Llopis 2010).

En aquest context, Caterina Albert i Paradís, Víctor Català (1869-1966) presentada en castellà l'any 1904 per Emilia Pardo Bazán a les pàgines d'Helios i a partir de la seva lectura de Drames rurals entre els nous i valuosos novellistes $\mathrm{i}$ contistes espanyols ordenats per procedència regional, $\mathrm{i}$ destacada escripturalment pels signes de fatalitat i de percepció de l'element tràgic en la realitat més humil a la seva narrativa, també pel vigor de les seves observacions i expressió literàries-s'incorpora l'any 1907 al corpus català traduït al castellà 
amb el volum Vida trágica. Colección de cuentos signat per Ángel Guerra, pseudònim de José Betancourt Cabrera (1874-1950) qui traduí relats extrets de Drames rurals i d'Ombrívoles, i amb la versió de Creu i ratlla per part de Gregorio Martínez Sierra (1881-1947) a les pàgines de Renacimiento, totes dues presències des de casa editorial i revista amb seus madrilenyes (Ribera Llopis 2007: 254-255, 173-177, 200-201). Prolífic 1lindar que aquella mateixa data es nodreix amb Soledad. Novela catalana, traducció de Francisco J./X. Garriga (n. 1864), volum sobre el qual haurem de tornar, la narrativa de Víctor Català continuarà atraient l'interès traductor. Pel que fa al període tractat, ens ho proven, fins a l'any 1921, quatre volums més $i$, fins a l'any 1931, unes altres divuit entrades en set publicacions periòdiques; es tracta d'un significatiu corpus a propòsit del qual ens hem plantejat l'existència de l'autotraducció i un original en castellà per part de l'escriptora, material que no exclou la possibilitat de noves troballes (Ribera Llopis 2007: 170-220).

Dins aquest corpus focalitzem la presència i l'aportació de Rafael Marquina (1871-1960), de formació universitària barcelonina en Filosofia i Lletres, amb activitat com a crític teatral en premsa de Barcelona i Madrid -matèria i mitjans en els quals destacaria per la fundació de la revista Teatralia (1908)- i autor estrenat de peces dramàtiques en català. Actant cultural que es personalitzarà fins a la seva partida i instal lació a Cuba des de l'any $1935 \mathrm{com}$ a un dels interlocutors indispensables en l'esmentat diàleg literari catalano-castellà de preguerra, ben particularment per via de la traducció. Traductor respectat per versions de Mme. de La Fayette, Alexandre Dumas, Joseph Conrad o Luigi Pirandello, tot passant per Curial $i$ Güelfa, abastarà la literatura dramàtica catalana d'Àngel Guimerà a Adrià Gual. En aquesta línia i entre 1920 i 1921, donarà a conèixer editorialment en castellà mostres exemplars de prosistes modernistes i noucentistes catalans com Raimon Casellas, Josep Pou i Pagès, Alfons Maseras, Pompeu Crehuet, Eugeni d'Ors, també Andreu Nin.

En aquest entramat de dates $i$ autors s'inclouen les seves traduccions de narrativa de Víctor Català:

- Dramas rurales. Novelas breves. Madrid, Calpe, 1921. Col. Universal, núms. 415, 416.

- La madre ballena. Madrid, Ediciones de 'La Pluma', 1921.

- La hija del Carolí. Madrid, La Pluma, año II, núm. 17, octubre de 1921.

El primer lliurament inclou Parricidi / Parricidio, Agonia / Agonía, Ombres / Sombras, L'explosió / La explosión, 'Nochebuena' / Nochebuena, Daltabaix / Batacazo i L'enveja / El antojo, de Drames rurals; Ànimes mudes / Almas mudas d'Ombrívoles; i Sota el cel / Bajo el cielo i Contraclaror / Contraluz de Caires vius. El contingut del segon volum prové quasi absolutament de l'aplec que li dóna títol - La Mare-balena / La Madre Ballena, Temptació / Tentación, Enaiguament / Pelusa, Croquis / Cróquis, Substitució / Sustitución, En Pelifet I Pelife - seguit de Conformitat / Conformidad d'Ombrívoles. Finalment, La hija de Carolí és traducció de Novel-leta, de La Mare-balena que, d'acord amb el que se'ns informa, no s'havia inclòs en l'aplec immediatament anterior per la 
seva extensió i havia estat substituiit pel relat esmentat Conformitat (Ribera Llopis 2007: 191, 210).

Les dues col-leccions de contes van acompanyades, respectivament sense $\mathrm{i}$ amb signatura, per sengles textos introductoris de Rafael Marquina (Ribera Llopis 2007: 188, 191-192). Basti ara recordar que el seu autor informa des de l'inici del seu projecte editorial de més llarga durada davant la rellevància de l'obra de Víctor Català a les lletres catalanes; també del corresponent èxit de públic i crítica; així mateix, de l'abast que cal donar a la marca literària de ruralisme $\mathrm{i}$ al terme drama rural com a gènere literari. Amb indicis d'advertiment des del primer dels dos texts, el segon explícita la seva repulsa al rebuig que estava rebent l'autoritat modernista des de determinats «cenáculos», sotmesos a «la adopción de todas las novedades». Doncs, les traduccions castellanes de Rafael Marquina i no només les de Víctor Català -majoritàriament d'adscripció modernista i malgrat no desestimi l'obra orsiana- no deixen de compondre un front de defensa dels valors d'arrel modernista. Som del criteri que es tracta d'un posicionament per part de Rafael Marquina, de manera pública oposat a l'atac d'ordre noucentista contra els que ja s'haurien de reconèixer com a autoritats del propi sistema literari.

La recepció crítica coetània d'aquest material se'ns documenta per via d'una ressenya de Cipriano Rivas Cherif (1891-1967) a propòsit del segon del volums publicats el 1921 i apareguda a La Pluma, al número 16 d'aquell mateix any (Ribera Llopis 2007: 265-266). El seu autor incideix en les consideracions critiques dutes a terme pel prologuista i traductor; a més considera l'autora catalana pertanyent a la categoria d'un art mediterrani d'abast universal a partir del local, vora altres exponents com a Giovanni Verga; i determina que és «la mejor novelista española», judici en la coincidència del qual no abundarem ara, però que fou sotasignat per altres valors literaris del moment com Concha Espina. Res, però, no se'ns diu de la traducció.

En canvi sí es pronuncia i en contra dels criteris traductors de Rafael Marquina, Matilde Ras (1881-1969), constant interlocutora de Víctor Català i una més d'aquestes veus que sustentaven la primacia literària de l'escalenca amb horitzó peninsular. Entre altres pàgines privades i publiques sobre la seva escriptura, Matilde Ras havia ressenyat l'aparició catalana de La Mare-balena el 1920 a Estvdio. Revista mensual, al número de setembre d'aquell mateix any, i jutjava negativament les decisions del traductor. En carta del dia 12 d'octubre de 1931 (Ribera Llopis 2007: 193) ${ }^{2}$-data que permet generalitzar els seu judicis sobre el conjunt de les traduccions enllestides per Marquina i epístola on la seva sotasignada informa voler traduir algun relat de Contrallums-, Matilde Ras, qui es presenta junt amb la seva mare com a traductores «archiconcienzudas» que sovint l'hauran de molestar amb consultes lingüístiques, pontifica: «Le confieso que me indignaron unas traducciones que de cuentos de V. hizo

2 L'epistolari de C. Albert i Paradís està dipositat a la Casa-Museu Víctor Català (L'Escala, Girona). La relació de les cartes revisades en aquestes pàgines respon a la documentació, lectura i ordenació inclosa en Ribera Llopis, 2007 (v. pp. 325-328). Pel que fa a la seva transcripció, es respecta l'ortografia dels originals, només regularitzem els accents. 
Marquina, suprimiendo o alterando frases enteras donde se le antojó, gazapos que con mi don de atención para lo que me interesa, cacé al vuelo».

Sobre la figura i el criteris traductors de Rafael Marquina ha versat la Dra. A. Hurtado Díaz en diverses ocasions. En l'aportació que considerem més precisa i amb la vàlua afegida d'un eficaç exercici comparatiu (Hurtado Díaz 2005: 89-93) l'estudiosa destaca que amb Angel Guerra només coincideixen en triar la narració Ánimes mudes per a les respectives seleccions. Mentrestant d'aquest últim el separa la seva competència lingüística per ésser nadiu català. Contrastant un paràgraf de l'esmentat relat i si es comparen ambdues traduccions, segueix A. Hurtado Díaz, s'avala com a «molt més literal i semàntica» la de Rafael Marquina, malgrat el desencert de la translació d'algun terme. Li lloa, això sí, la solució per a paraules culturals o culturemes - «hereu», «pubilla» > «heredero», «heredera» / «mozo», «muchacha» en Ángel Guerra-, però li retreu la corresponent solució per als noms propis, els quals Rafael Marquina ni conserva ni castellanitza, sinó que inventa formes de difícil pronuncia en castellà. En tot cas, per a la citada estudiosa, resulta «excel·lent» la traducció de Rafael Marquina, la qual encara considera vàlida per als lectors actuals i reeditable. En canvi, no contempla les omissions de l'original que sí troba en la versió d'Ángel Guerra. Aquest últim és un tret que ja havia assenyalat Víctor Català (17VI-1919) en una de les lletres després tractades i dirigida a Rafael Marquina. Aquella llicència que també es permetia Rafael Marquina, segons la recordada crítica epistolar de Matilde Ras, no sembla comprovar-se en el text tractat. Potser la diferent advertència crítica entre una i altra lectora la imposen la narració o els fragments elegits per A. Hurtado Díaz per apropar-se als diferents criteris dels dos traductors atesos.

\section{II.- TRADUCCIONS I CONSELLS I JUDICIS EPISTOLARS}

L'esmentada carta de Matilde Ras desqualificant les traduccions de Rafael Marquina ja ens prova l'interès informatiu de l'epistolari de Víctor Català en aquest darrer sentit. Si amb anterioritat a aquest advertiment dèiem que tornaríem sobre la traducció castellana de Solitud era precisament perquè, tot atenent a l'intercanvi postal entre l'escriptora i Francisco J. Garriga, responsable de la versió castellana, se'ns il·lumina des dels seus documents el camí cap al text publicat i ens permet contrastar criteris entre els dos implicats en el resultat, l'autora i el traductor. Conservada una extensa carta de puny i lletra de Caterina Albert i Paradís (22-IV-1906) i trenta-set signades per Francisco J./X. Garriga -entre els anys 1905 i 1939; disset fins l'any 1907, data de publicació de la versió en castellà- aquest corpus permet resseguir ben informats l'itinerari de la relació entre tots dos $i$, en bona mesura, la gestació del text resultant (Ribera Llopis 2007: 178-186, 307-312).

Si tenim en compte que la primera lletra conservada de Francisco J. Garriga (29-XII-1905) no ens situa en l'inici puntual de la relació amb l'escriptora, resumirem ara i aquí que ja s'hi informa tenir enllestida bona part de la tasca, sempre pendent de revisió; també es notifica enviar-li un fragment a tall de mostra d'una traducció que estaria acabada l'abril següent (1-IV-1906). A ban- 
da dels continguts que ens introdueixen en la qüestió editorial -més interessant és que seguia pendent la presentació de la mostra promesa del text traduït-, a partir d'aquest doble llindar ens plantegem que, d'acord, amb els documents consultats, sembla no haver-se donat un intercanvi entre autora $\mathrm{i}$ escriptor sobre el trànsit de l'original a la versió en castellà.

És aquí on l'única carta de Caterina Albert i Paradís ens serveix com a guia i document exemplar per inferir el binomi autoria\&traducció que encapçala el títol de la nostra proposta. Víctor Català confia que la revisió del text del qual, per fi, ha rebut una mostra esmenarà errades rellevants -catalanismes, falses correspondències amb veus castellanes i errònies fonts de contrast per part del traductor- tant com espera ésser consultada i informada. Tot això en una llarga missiva on l'autora corregeix alguna traducció puntual. En particular s'interessa per la variant dialectal elegida en donar veu al Pastor. Francisco J. Garriga (¿?IV/V-1906) li respon tot lamentant la falta de contacte prèviament adduïda per l'escriptora; justificarà haver-se plantejat una versió literària però, no obstant aquest to justificatiu, no deixa de respondre i defendre's de les apreciacions més concretes la seva interlocutora. Cartes posteriors del traductor ens documenten que aquest exercici de contrast i correcció mutus va seguir endavant, mentre es perseguia retardar la publicació, també poder corregir sobre les galerades (5-XII-1906; 31-III-1907). El que Víctor Català digués en les cartes no conservades i les seves consideracions lingüístiques i literàries, tot això resta implícit en el que escriu, pregunta i proposa o defèn el traductor. Més enllà de la data de 1907 i entre contactes cada vegada més distanciats i neutres, la relació entre ambdós va diluint-se. En ocasions, Francisco J. Garriga no aconsegueix cap resposta. Serà amb motiu del projecte plantejat l'any 1936 de reeditar Soledad per Editorial Joventut, que l'antic traductor manifesta tenir una «acurada correcció de l'edició, que penso que millorarà molt» (24-IV-1936). Malgrat aquest bon propòsit, davant aquesta afirmació juntament amb el prec de la conformitat de l'autora, el traductor haurà d'insistir. Això per haver d'admetre a la fi apreciar que la falta de resposta no fou altra cosa que una resposta negativa, en tot cas a propòsit d'una reedició que no es duria a terme. Objectivament, almenys d'acord amb els documents conservats, s'imposa el silenci de l'autora

Davant aquest resumit itinerari, nosaltres som de l'opinió que Víctor Català no restà satisfeta ni amb l'experiència ni amb el resultat final pel que fa a la seva relació literària amb Francisco J. Garriga. Traducció positivament informada i valorada per A. Hurtado Díaz (2007: 174-176), pensem que no és aquesta la impressió que es desprèn de l'epistolari a propòsit del judici de Víctor Català. En tot cas i només a tall d'exemple, si hem tornat sobre aquest cas concret, és per tenir en compte el tipus de relació que Víctor Català podia establir amb els seus traductors; també per prendre en consideració l'epistolari conservat com a font informativa al respecte. Això i en particular atenció a la tasca del traductor, per part d'una escriptora que se'ns mostra tan meticulosa amb el propi idioma com respectuosa amb el castellà. Qüestió que es pot comprovar ben concretament quan coneixem els seus criteris a propòsit de la consciencia lingüística i sobre l'ús literari de les llengües (Ribera Llopis 2007: 48-64). Serà aquest puny de consideracions el que ens farà tenir en compte la informació epistolar que ens pugui clarificar, més enllà del conjunt de traducci- 
ons enllestit per Rafael Marquina, el diàleg entre creadora i traductor. Haver escoltat fins aquí les veus i haver contrastat els documents que, unes i altres, ens informen sobre les traduccions coetànies de Víctor Català té aquesta puntual funció.

\section{L'AUTORA, EL SEU TRADUCTOR I UN ALTRE FINAL PACTE DE SILENCI}

Del tàndem Caterina Albert i Paradís i Rafael Marquina se'ns conserven -juntament amb una nota o esborrany manuscrit del permís i condicions de la publicació per a la casa editorial Calpe- tres documents epistolars dels anys 1919 i 1921 de part de l'autora i vuit del seu interlocutor dels mateixos anys. És cert que del conjunt de documentació ordenada a propòsit de les traduccions de Rafael Marquina sobre textos de Víctor Català (Ribera Llopis 2007: 188-190, 192-193, 210), la informació corresponent a Novel-leta / La hija del Carolí no va més enllà dels tràmits editorials; dada per la qual ens reafirmem en què, material excedent del volum La madre ballena, passà de l'editorial dirigida per Manuel Azaña, La Pluma, a l'homònima revista de la casa editora, destí compartit amb la ressenya abans rescatada, signada per Cipriano Rivas Cherif. No obstant això, l'intercanvi epistolar entre Caterina Albert i Paradís i Rafael Marquina té un ben diferent abast pel que fa a la resta de les traduccions publicades.

Iniciada la correspondència per Rafael Marquina (29-V-1919), amb carta dirigida a l'Escala, és expressió del seu màxim respecte per l'escriptora destinatària de les seves paraules; el signatari s'autopresenta a més com a traductor-difusor de les lletres catalanes - per les seves bones relacions editorials també avançades pel futur traductor, en situació idònia «per a continuar [...] aquesta tasca de divulgació en una biblioteca popular»-i sol-licita el permís per enllestir Drames rurals - «estant ja traduïda "Solitut"»-.

La immediata resposta signada des de Barcelona per l'escriptora (3-VI1919) serà triplement positiva: sense oblidar condicions editorials, gaudeix honrosament que «ploma de tanta galania y competència com la de V. s'ocupi en girar al castellà mos assaigs modestíssims»; l'informa de les narracions prèviament traduïdes, amb la proposta d'ampliar la selecció amb tria dels dos aplecs posteriors -Caires vius i Ombrívoles, comptant també amb les que haurien d'aparèixer en el «volumet» projectat per l'Editorial Catalana, amb aquelles altres que restaven «disperses en revistes y periòdichs»-; i, a banda d'aquest suggeriment, li respecta la llibertat d'elecció i els criteris de les seves versions, justifica les decisions de cada traductor, sempre «naturalment que tinga criteri y bon gust» i es mostra entenedora que cadascú «fa de lo que tradueix una obra nova» que caldrà acceptar com a personal, més encara tractant-se «d'un literat quina vàlua coneixem $\mathrm{i}$ admirem prou tots $\mathrm{i}$ al que tan de bo deuhen le lletres y'ls autors catalans»».

Llindar del tot diferent al que enllaçava les signatures de Caterina Albert $\mathrm{i}$ Paradís i de Francisco J. Garriga, ara Víctor Català marcarà autorialment l'itinerari castellà dels seus contes. Doncs, és així com Rafael Marquina (13-VI-1919) 
pot posar-se a la feina amb el vist i plau de l'autora, amb la pertinent indicació de per on pot anar la seva tria i amb la porta oberta per a qualsevol tipus de consulta que sempre podrà fer-se a mesura que avanci la seva tasca i no a partir d'una primera versió tancada. Si en aquesta mateixa carta el traductor celebra la feina que l'espera com a «festa espiritual», l'autoritat literària agraeix el seu oferiment com a «veritable honor» (16-VI-1919).

A banda de l'acurada atenció a les qüestions editorials, Rafael Marquina, en correlativa seqüència epistolar (11-VII-1919, 16-II-1920, 20-II-1921) i sempre atenent qüestions formals entremig, la fa partícip del seu treball -«Dintre d'unes setmanes tindré el gust d'enviarli mostres de la traducció juntes amb la súplica de la seva benvolença» (11-VII-1919)- i justifica la inclusió d'Ànimes mudes, malgrat la traducció ja existent -«per què amb 'Conformitat' i 'L'enveja' crec jo que poden servir per a espaiar amb la seva nota més suau i plàcida la ferma negror de les altres narracions» (16-II-1920)-, tot pregant-li establir l'ordre de publicació dels textos. Ens interessa aquí destacar com, en defendre la seva versió del conte esmentat, el traductor fa valer una comprensió de l'univers literari de Víctor Català que, després i no obstant això, deixa en mans de la seva creadora, com a absolut demiürg. Per la seva banda, l'escriptora (17-VI1919) ja li havia passat la referència a les traduccions que coneixia; lamentava les que podrien haver-se fet sense cap permís i, al mateix temps i sempre interessada per possibles i futures traduccions com a mitjà divulgador de la seva obra, preguntava, això sí, sobre com quedaria condicionada pel contracte que calia tancar.

Rafael Marquina (24-III-1921) informa de la revisió del text i de la correcció de proves, ja ben a prop de la imminent aparició de les seves traduccions; i, al mateix temps, amb l'exemplar de La Mare-balena enviat per l'autora a les seves mans i celebrant regal i lectura «amb la dolçor de la fruita madura», ja ens parla d'un nou lliurament en castellà. Ara per part de La Pluma, interessat el seu director, Manuel Azaña, per l'«elogi» que ell mateix ha fet. Això sí, sempre informant acuradament a Víctor Català de les qüestions contractuals; $i$ honrat per «ésser el propagador en castellà de l'obra meravellosa que tant admiro de qui ha sapigut enlairar la nostra literatura». Així i en tot cas amb el permís de l'autora, vol posar-se «immediatament a l'agradosa tasca de la traducció». I malgrat poc després i amb l'enviament dels exemplars dels definitius Dramas rurales. Novelas breves hagi de lamentar certes «errades d'impremta», el traductor es mostrarà humil davant l'original enllestit i prega el judici de l'autora:

Demés, bé sé prou que no he pogut arrivar ni amb molt a conservar en el meu modest trevall tota la formosor i vigoria de les admirables narracions, però li prego que'n prengui la bona voluntat. [...] Li estimaría moltíssim m'escribís dientme tot el que en la meva traducció ha trobat digne de repte - tinc por de que ne será molt - i també, si és cas, el que menys l'hagi desplagut. Mentre tant, no m'atreveixo a entregar a La pluma la traducció de La mare balena. (20-V-1921).

Intranquil Rafael Marquina per la tardança de la resposta i immediatament dubitatiu pels termes potser massa generals per part de l'escriptora, les cartes 
respecte d'aquest primer lliurament semblen deixar el traductor en un impass; en un estat que potser se'ns podria aclarir si no es tingués l'interrogant sobre la pèrdua postal de cartes i la mancança d'algunes respostes entre ells dos que, de vegades, es notifica en els textos existents:

Rebo la seva lletra. No he rebut la que vostè diu que va escriurem parlantme de la traducció de Drames rurals. Sento que no hagi rebut les meves. Però moltíssim més he sentit no rebre la de vostè, perquè m'ha tingut molt intranquil el seu silenci que no podia interpretar més que com a senyal de que li havia desplagut força la meva traducció dels drames i que'm feia la caritat de no dirm'ho. Això, afegit a no haverme escrit res tampoc respecte a la segona traducció m'afermava més encara en la gran certesa del meu fracàs. Quelcom se m'ha esvaït en llegir la seva amable lletra, però sento encara inquiet per el que fa referencia als drames. ¿Puc esperar unes paraules ben sinceres de vostè respecte an això? (17-IX-1921)

Enmig de tots aquests dubtes per part de Rafael Marquina, un esborrany de carta enviada per Caterina Albert i Paradís (26-III-1921) segueix documentant la seva confiança en el seu traductor: «Ab molt de gust veure sigui $\mathrm{V}$. el que vagi traduint contes meus, car conech la seva competència». Això, no sabem si qualificar-ho de lacònic o simplement de reiteratiu; en tot cas, resta escrit abans de tornar a qüestions d'ordre editorial i de mostrar l'interès que la signatària tenia a propòsit de la traducció com a eina divulgativa de la seva obra, referintse en aquesta ocasió a un projecte nord-americà que fins ara no hem pogut confirmar.

Més enllà d'aquells precs i d'aquestes darreres paraules, s'obrí el silenci epistolar entre els nostres dos protagonistes. Potser manquen documents, tal vegada res més quedà per escrit. Per la seva banda, Rafael Marquina, al llarg de les seves missives, sempre havia encapçalat les seves lletres amb la destinació $\mathrm{a}$ «Srta. » $\mathrm{o}$ «Na Caterina Albert», però redactava el seu contingut dirigint-se a Víctor Català. En ocasions en femení - «Molt distingida i admirada Víctor Català» (29-V-1919) - o en d'altres en masculí - «Admirat Víctor Català» (20-II1921), «Admirat company de lletres» (24-III-1921), «Mestre admirat» (20-V1921), «Admirat confrare» (17-IX-1921)-. Sembla que el pseudònim s'imposava en el moment de reconèixer l'autoria literària. No obstant això i com a mostra del respecte i del reconeixement per part de Rafael Marquina a l'escriptora Víctor Català, també però de la coneixença de la persona Caterina Albert i Paradís, només ens queda transcriure el seu «Molt agraï al honor que m'ha fet, el seu devot admirador i amic, Rafael Marquina», el comiat de la darrera carta conservada.

\section{BIBLIOGRAFIA}

Bacardí, M., «La traducción del catalán al castellano. Una tradición aleatoria», Visat, 9, 2010 [en línea], [consulta: 13.06.2018], [http://www.visat.cat/articles/cat/21/la-traduccio-del-catala-al-castella-una-tradicio-aleatoria.html] 
Català, Víctor (1921) Dramas rurales. Novelas breves. La traducción del catalán ha sido hecha por Rafael Marquina, Madrid, Calpe, Col. Universal, núms. 415, 416.

Català, Víctor (1921) La madre ballena. Traducción del catalán por Rafael Marquina, Madrid, Ediciones de 'La Pluma'.

Català, Víctor (1921) «La hija del Carolí. Traducción de Rafael Marquina», La Pluma 17.

Hurtado Díaz, A. (2007) «Una dissonància misteriosa. Les traduccions castellanes de Víctor Català al primer terç del segle XX», dins M. Pesarrodona coord., Caterina Albert. Cent anys de la publicació de 'Solitud', CSIC Generalitat de Catalunya, pp. 171-182.

Hurtado Díaz, A. (2005) «Ángel Guerra i Rafael Marquina, traductors al castellà de Drames rurals i Ombrívoles de Caterina Albert, 'Víctor Català'», dins Gibert, M. M. i Ortín, M. eds., Gèneres i formes en la literatura catalana d'entreguerres (1918-1939), Lleida, Punctum\&Trilcat, pp. 85-96.

Ribera Llopis, J. M. (2010) «Els escriptors finiseculars a la llar hispana i els fluents llindars d'un model d'interliterarietat», Caplletra 48, pp. 71-92

Ribera Llopis, J. M. (2007) Projecció i recepció hispanes de Caterina Albert $i$ Paradís, Víctor Català, i de la seva obra, Girona, CCG Edicions. 